Tropical Journal of Pharmaceutical Research July 2018; 17 (7): 1295-1299

ISSN: 1596-5996 (print); 1596-9827 (electronic)

(1) Pharmacotherapy Group, Faculty of Pharmacy, University of Benin, Benin City, 300001 Nigeria.

\title{
Studies on intestinal passage of flumequine and oxytetracycline-loaded MIL-100 (Fe) in the presence of divalent ions
}

\author{
Fatma Ben Ayed ${ }^{1,2,4 *}$, Godefroy Mamadou ${ }^{2}$, Hanae Naceiri Mrabti ${ }^{2,3}$, Nicolas \\ Limas-Nzouzi ${ }^{2}$, Bruno Eto ${ }^{2}$, Sâad Saguem ${ }^{1}$ \\ ${ }^{1}$ Laboratory of Professional Metabolic Biophysics and Toxicology Environment, Faculty of Medicine, University Of Sousse, \\ Hamed El Karoui Avenue, 4000 Sousse, Tunisia, ${ }^{2}$ TransCell-Lab Laboratory, Faculty of Medicine Xavier Bichat, University of \\ Paris Diderot - Paris 7, 16 rue Henri Huchard 75890 Paris, France, ${ }^{3}$ Faculty of Medicine and Pharmacy, Laboratory of \\ Pharmacology and Toxicology, University of Mohammed V, Av. Mohamed Belarbi El Alaoui, 6203 Rabat-Instituts, Maroc, \\ ${ }^{4}$ Faculty of Sciences, Bizerte, University of Carthage, 7021 Jarzouna, Tunisia
}

*For correspondence: Email: go.mad289@gmail.com; Tel: +330609651425

\begin{abstract}
Purpose: To compare the intestinal absorption of flumequine (FLM) and oxytetracycline (OTC) in encapsulated and non-encapsulated forms in the presence of divalent ions.

Methods: MIL-100 (Fe) nanoparticles were synthesized under hydrothermal conditions from a mixture of iron carboxylate and trimesic acid (organic linker), and then used to encapsulate OTC and FLM. Permeation of the various formulations through the mouse jejunum was evaluated in Ussing chamber. Results: There was significant $(p<0.05)$ increase in the intestinal flux of encapsulated OTCS (OTCNPs, $\left.0.072 \pm 0.016 \mu \mathrm{g} / \mathrm{h} / \mathrm{cm}^{2}\right)$, compared to that of non-encapsulated OTCs $\left(0.021 \pm 0.05 \mu \mathrm{g} / \mathrm{h} / \mathrm{cm}^{2}\right)$. Moreover, the intestinal flux of encapsulated FLMs (FLM-NPs, $0.045 \pm 0.006 \mu \mathrm{g} / \mathrm{h} / \mathrm{cm}^{2}$ ) was significantly higher than that of non-encapsulated FLMs $\left(0.004 \pm 0.0008 \mu \mathrm{g} / \mathrm{h} / \mathrm{cm}^{2}, p<0.05\right)$.

Conclusion: The intestinal flux of encapsulated antibiotics is significantly enhanced in the presence of MIL-100 (Fe), thereby preventing their chelation by divalent ions in solution, and thus improving their intestinal absorption.
\end{abstract}

Keywords: MIL-100 (Fe), Intestinal bioavailability, Mice, Oxytetracycline, Flumequine

\begin{abstract}
This is an Open Access article that uses a funding model which does not charge readers or their institutions for access and distributed under the terms of the Creative Commons Attribution License (http://creativecommons.org/licenses/by/4.0) and the Budapest Open Access Initiative (http://www.budapestopenaccessinitiative.org/read), which permit unrestricted use, distribution, and reproduction in any medium, provided the original work is properly credited.
\end{abstract}

Tropical Journal of Pharmaceutical Research is indexed by Science Citation Index (SciSearch), Scopus, International Pharmaceutical Abstract, Chemical Abstracts, Embase, Index Copernicus, EBSCO, African Index Medicus, JournalSeek, Journal Citation Reports/Science Edition, Directory of Open Access Journals (DOAJ), African Journal Online, Bioline International, Open-J-Gate and Pharmacy Abstracts

\section{INTRODUCTION}

Flumequine (FLM) from the quinolone family, and oxytretracycline (OTC) from the tetracycline family are two broad-spectrum antibiotics that are widely used in veterinary medicine [1]. Indeed, FLM was the first quinolone used in human and veterinary therapy [2]. It is currently used extensively in fish farming and aquaculture for the treatment of bacterial diseases such as enteric infections and gill diseases. Similarly, OTC is used in various curative treatments in animal breeding, especially in aquaculture and fish farming [1]. However, despite the good oral bioavailabilities of both antibiotics, their intestinal absorptions are altered by concomitant 
administration of foods and antacids containing di- or trivalent cations such as $\mathrm{Al}^{3+}, \mathrm{Mg}^{2+}$ and $\mathrm{Ca}^{2+}$, which form non-absorbable complexes (chelates) [3,4]. This phenomenon reduces the amount of active ingredient $(\mathrm{Al})$ available for absorption [4]. Thus, it can significantly reduce the antibacterial activities of the administered antibiotics [4]. This constitutes a major concern because in animal breeding, the preferred practice in the treatment of certain infections entails the incorporation of certain drugs in the diet. Indeed, many studies have focused on chelation phenomena that alter oral bioavailability in situations of simultaneous administration of antacids containing aluminum and quinolone [5]. This chelation has been observed also with OTC. The protection of antibiotics against divalent ions can increase their intestinal passage and thus, their antibacterial activities.

Major research efforts are devoted to the development of new pharmaceutical formulations based on nanoparticles capable of protecting and controlling the release of Als in the intestine. This is the case with the metal organic framework of iron III [MIL-100 (Fe) hybrid solid] [6], which possesses the unique power of molecular inclusion. It offers protection to the $\mathrm{Al}$ of interest sensitive to possible interactions with certain constituents of the harmful gastrointestinal environment. It is in this perspective that MIL-100 $(\mathrm{Fe})$ is used to protect aspirin against enzymatic degradation (for better gastrointestinal absorption), while protecting the patient from its irritating effects on the stomach [7]. The purpose of this work was to develop an oral formulation for protecting FML and OTC from divalent and trivalent ions in order to improve their bioavailability by encapsulating them in MIL-100 (Fe).

\section{EXPERIMENTAL}

\section{Materials}

D-glucose, bumetanide hydrochloride, trimesic acid and ferric chloride hexahydrate were obtained from Sigma (St. Quentin-Fallavier, France). Oxytetracycline and flumequine were products of Sigma (St. Louis, USA). MIL-100(Fe) nanocapsules were gifted by $F$. Ben Ayed of Lavoisier Institute, Versailles-Paris [6].

\section{Permeation studies}

\section{Animals}

Male mice (20 - $25 \mathrm{~g}$ ) were used in this study. They were provided by Janvier SAS (St
Berthevin, France), and were given feed and clean water ad libitum, and housed singly in metabolism cages. The experimental protocols and animal handling conformed with the provisions of the Guide for the Care and Use of Laboratory Animals of the National Institute of Health, and the research ethics of Diderot University - Paris 7, conformed Directive 2010/63/EU of the European Parliament and of the council [8].

Following an 18-h fast, the mice were subjected to sacrifice under carbon dioxide inhalation. Jejunum samples were excised, rinsed in isotonic Ringer's solution, and cut flat open through the mesenteric axis. The jejunum slices were then mounted in Ussing chambers in line with established procedure $[9,10]$.

\section{Determination of trans-epithelial electrical conductance}

The Ringer's solution ( $\mathrm{pH}$ 7.4) used comprised $25 \mathrm{mM} \mathrm{NaHCO}_{3}, 2.4 \mathrm{mM} \mathrm{K}_{2} \mathrm{HPO}_{4}, 115 \mathrm{mM} \mathrm{NaCl}$, $1.2 \mathrm{mM} \mathrm{MgCl}_{2}, 1.2 \mathrm{mM} \mathrm{CaCl}_{2}$, and $0.4 \mathrm{KH}_{2} \mathrm{PO}_{4}$. The solution was aerated continuously in the Ussing chambers at $37^{\circ} \mathrm{C}$ with air containing 5 $\% \mathrm{CO}_{2}$. The spontaneous transmural electrical potential difference (PD) between the mucosa of serosa jejunum and the mucosa of the luminal jejuna was determined through $3 \mathrm{M} \mathrm{KCl}$ containing $4 \%$ agar bridges on the two sides of the jejunum linked to high-impedance voltmeter and calomel half-cells. Through short-circuiting current $\left(I_{s c}\right), 0 \mathrm{mV}$ PD was sustained for the duration of the study $[11,12]$.

A continuous record of $I_{\mathrm{sc}}$, which is a measure of trans-epithelial ionic permeability, was produced with Biodaqsoft software. The $I_{\mathrm{sc}}$ adjusted for fluid resistance, is the net trans-epithelial ion flux when electrochemical gradient is absent. Transepithelial electrical conductance $\left(G_{t}\right)$ was estimated from Ohm's law as the inverse of resistance.

\section{Measurement trans-epithelial flux of OTC and FLM}

When a steady state was attained with respect to electrical parameters, pairs of jejunum tissues were matched based on their conductance values. Then, OTC and FLM were separately added to the mucosa chamber. At 60-min intervals, the other chamber was sampled in 1$\mathrm{mL}$ aliquots which were replaced on withdrawal with an equivalent volume of Ringer's isotonic solution. A total of 4 samples were collected (0 $240 \mathrm{~min}$ ) and subjected to UV measurements in a spectrophotometer at 327 (for FLM) and 374 
$\mathrm{nm}$ (for OTC). The absorbance values were used for the determination of unidirectional fluxes $\left(J_{m s}\right)$ [13].

\section{Statistical analysis}

Data are presented as mean \pm standard error of the mean (SEM), and analysed statistically with one-way analysis of variance (ANOVA) in combination with Dunnett's multiple comparison test. Values of $p<0.05$ were taken as indicative of statistically significant differences.

\section{RESULTS}

\section{Trans-epithelial flux of OTC and FLM}

The intestinal flux of encapsulated OTC (OTCNPs) increased significantly, relative to the fluxes of non-encapsulated OTCs (control) (Jms = $0.072 \pm 0.016 \mu \mathrm{g} / \mathrm{h} / \mathrm{cm}^{2}$ for OTC-NPs, versus $0.021 \pm 0.05 \mu \mathrm{g} / \mathrm{h} / \mathrm{cm}^{2}$ for OTC, $p<0.05$ ). In addition, the intestinal flux of encapsulated FLMs (FLM-NPs) increased significantly, compared to the flux of non-encapsulated FLMs (control) (Jms $=0.045 \pm 0.006 \mu \mathrm{gg} / \mathrm{h} / \mathrm{cm}^{2}$ for FLM-NPs, versus $0.004 \pm 0.0008 \mu \mathrm{g} / \mathrm{h} / \mathrm{cm}^{2}$ for FLM, $p<0.05$ ).

\section{Intestinal functional viability}

The physical and functional viabilities of the tissues are usually monitored at the end of the study by measuring the transport of electrogenic ions due to the tissue response after stimulation. Forskolin $(0.1 \mathrm{mM})$ was added to the serosal side of the tissue to induce electrogenic absorption [14], followed by bumetanide $(0.1 \mathrm{mM})$ on the same side, to induce inhibition of the generation of electrogenic ions. Variations in Isc indicate the physical and functional viabilities of the tissue at the end of the permeation studies [9]. The results are shown in Figure 1.

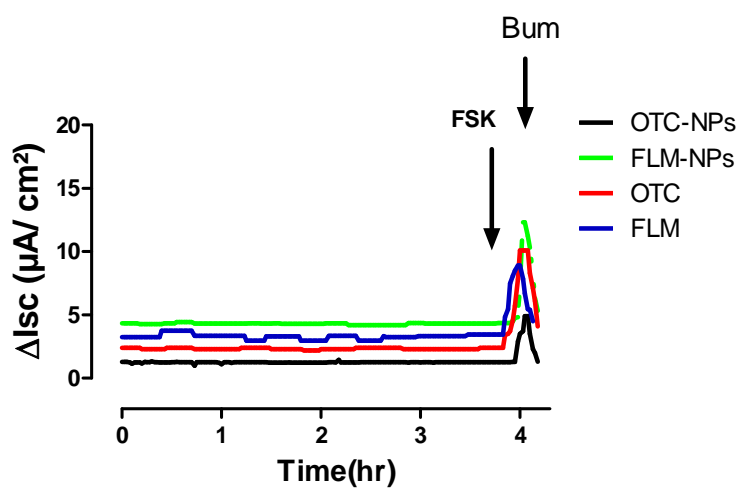

Figure 1: Recording of the effect Forskolin (Fsk) (0.1 $\mathrm{mM}$ ) and bumetanide (Bum) $5 \times 10^{-5} \mathrm{M}$ on short-circuit current (Isc) at the end of the permeation experiment $(4 \mathrm{~h})$. Fsk and Bum were added to the serosal side of the preparation. The variation in Isc indicated the physical and functional viabilities of the tissue at the end of the permeation studies

\section{DISCUSSION}

The usefulness of metal organic frameworks (MOFs) have been demonstrated in many applications, particularly in biomedicine due to their ability to encapsulate and release active molecules. Various studies have shown that MIL$100(\mathrm{Fe})$, an MOF, is widely used to encapsulate active molecules. Indeed, the use of nanoparticle derivatives of active ingredients is a common strategy for enhancing their systemic absorptions. Active ingredients can be encapsulated for intended release into the gastrointestinal medium or through the intestinal mucosa. Thus, flurbiprofen, a poorly-soluble antiinflammatory agent in aqueous solutions, has been encapsulated in nano MIL-100 (Fe), resulting in a relatively prolonged and promising release of the molecule [16].

In the present study, the antibiotics FLM and OTC were protected from divalent ions that hinder their intestinal absorptions by the formation of non-absorbable chelates through their encapsulation in MIL-100 (Fe). Indeed, available literature has shown that simultaneous production of quinolones with $\mathrm{Ca}^{2+}, \mathrm{Mg}^{2+}, \mathrm{Al}^{3+}$ leads to the formation of complexes [17] that reduce their intestinal absorptions, and thus their antibacterial activities [15]. This phenomenon of chelation by metal ions is also observed with tetracycline [3,4]. The antibiotics FLM and OTC are widely used in animal farming, especially in fish farming, in which the ionic composition of the marine environment is rich in divalent ions such as $\mathrm{Ca}^{2+}$ and $\mathrm{Mg}^{2+}$. However, for better treatment in the case of mass rearing, these antibiotics are mixed with fish feed. Hence, it is preferable to protect the antibiotics so as to ensure their optimum antimicrobial effects through their safe delivery.

In the present study, the permeations of encapsulated FLM and OTC in the Ussing chamber in the presence of Ringer's solution increased their intestinal passages 10 folds and 5 folds, respectively, when compared with controls.

These increases in permeation were probably due to the cage protection of MIL-100 ( $\mathrm{Fe}$ ) from the divalent ions which allowed the safe deliveries of the antibiotics. Moreover, iron may interact with the narrow junctions of intestinal epithelial cells, and thus increase the permeability of the intestinal wall [18]. This 
mechanism may explain the significant increases in the fluxes of the encapsulated antibiotics through the intestinal wall, relative to the free antibiotics.

\section{CONCLUSION}

The findings of this study indicate that encapsulation of active ingredients by MIL-100 (Fe) nanoparticles shows a strong potential for improving the oral bioavailability of these active molecules. Thus, nanoparticle encapsulation can be considered a good platform for formulations aimed at protecting antibiotics such as flumequine and oxytetracycline which are susceptible to chelation by divalent and trivalent ions.

\section{DECLARATIONS}

\section{Acknowledgement}

The authors acknowledge Patricia Horcajada and Christian Serre at the Lavoisier Institute (UMR 8180 CNRS-UVSQ) for their technical assistance and helpful advice concerning the synthesis of MIL-100 (Fe). We would also like to thank Mrs Laila MAHFOUDHI, Major Professor of English in the Sfax Faculty of Sciences (University of Sfax Tunisia) for proofreading and editing the language of the manuscript.

\section{Conflict of Interest}

No conflict of interest associated with this work.

\section{Contribution of Authors}

The authors declare that this work was done by the authors named in this article and all liabilities pertaining to claims relating to the content of this article will be borne by them.

\section{REFERENCES}

1. Caudell MA, Quinlan MB, Subbiah M, Call DR, Roulette CJ, Roulette JW, Roth A, Matthews L, Quinlan RJ: Antimicrobial use and veterinary care among agropastoralists in northern Tanzania. PloS one 2017; 12 : e0170328.

2. Anadón A, Martínez MA, Martínez M, De La Cruz C, Diaz MJ, Martínez-Larrañaga MR: Oral bioavailability, tissue distribution and depletion of flumequine in the food producing animal, chicken for fattening. Food Chem Toxicol 2008; 46: 662-670.

3. Carlotti B, Cesaretti A, Elisei F: Complexes of tetracyclines with divalent metal cations investigated by stationary and femtosecond-pulsed techniques. Phys. Chem. Chem. Phys 2012; 14: 823-834.

4. Bushra R, Aslam N, Khan AY: Food-drug interactions. Oman Med J 2011; 26: 77.

5. Hartshorn EA, Lomaestro BM, Bailie GR: Quinolonecation interactions: a review. DICP 1991; 25: 12491258.

6. Horcajada $P$, Surblé $S$, Serre $C$, Hong $D-Y$, Seo $Y-K$, Chang J-S, Greneche J-M, Margiolaki I, Férey G: Synthesis and catalytic properties of MIL-100 (Fe), an iron (III) carboxylate with large pores. Chem Commun 2007; 27: 2820-2822.

7. Singco $B$, Liu $L-H$, Chen $Y-T$, Shih $Y-H$, Huang $H-Y$, Lin $\mathrm{C}-\mathrm{H}$ : Approaches to drug delivery: Confinement of aspirin in MIL-100 (Fe) and aspirin in the de novo synthesis of metal-organic frameworks. Micropor. Mesopor. Mat 2016; 223: 254-260.

8. European Commission. Directive 2010/63/EU of the European Parliament and of the council of 22 September 2010 and of the council of 22 September 2010 on the protection of animals used for scientific purposes 2010.

9. Mamadou G, Charrueau C, Dairou J, Nzouzi NL, Eto B, Ponchel G: Increased intestinal permeation and modulation of presystemic metabolism of resveratrol formulated into self-emulsifying drug delivery systems. Int J Pharm 2017; 521: 150-155.

10. Souirti Z, Loukili M, Soudy ID, Rtibi K, Ozel A, LimasNzouzi N, El Ouezzani S, Eto B: Hibiscus sabdariffa increases hydroxocobalamin oral bioavailability and clinical efficacy in vitamin B12 deficiency with neurological symptoms. Fundam Clin Pharmacol 2016; 30: 568-576.

11. Mathieu J, Mammar S, Eto B: Automated measurement of intestinal mucosa electrical parameters using a new digital clamp. Methods Find Exp Clin Pharmacol 2008; 30: 591-598.

12. Meddah B, Limas-Nzouzi N, Mamadou G, Miantezila J, Soudy ID, Eto B: Antisecretory effect of prescribed appetite stimulator drug cyproheptadine in rat intestine. Fundam Clin Pharmacol 2014; 28: 303-309.

13. Dossou-Yovo F, Mamadou G, Soudy ID, Limas-Nzouzi N, Miantezila J, Desjeux J-F, and Eto B: Metronidazole or Cotrimoxazole therapy is associated with a decrease in intestinal bioavailability of common antiretroviral drugs. PloS one 2014; 9: e89943.

14. Terres AM, Pajares JM, Hopkins AM, Murphy A, Moran A, Baird AW, Kelleher D: Helicobacter pylori disrupts epithelial barrier function in a process inhibited by protein kinase $C$ activators. Infect Immun 1998; 66: 2943-2950.

15. Sultana N, Humza E, Arayne MS, Haroon U: Effect of metal ions on the in vitro availability of enoxacin, its in vivo implications, kinetic and antibacterial studies. Quim Nova 2011; 34: 186-189.

16. Haydar MAL, Abid HR, Sunderland B, Wang S: Metal organic frameworks as a drug delivery system for flurbiprofen. Drug Des Devel Ther 2017; 11: 2685. 
Ayed et al

17. Wallis SC, Gahan LR, Charles BG, Hambley TW, Duckworth PA: Copper (II) complexes of the fluoroquinolone antimicrobial ciprofloxacin. Synthesis, $X$ ray structural characterization, and potentiometric study. J. Inorg. Biochem 1996; 62: 1-16.
18. Ferruzza S, Scacchi M, Scarino ML, Sambuy Y: Iron and copper alter tight junction permeability in human intestinal Caco-2 cells by distinct mechanisms. Toxicol In Vitro 2002; 16: 399-404. 